\title{
Exposure to the advertisement of toombak at the point-of- sale among adolescents in Khartoum State, Sudan: A cross- sectional study
}

\author{
Hatim M. Almahdi 1,2, Raouf W. Ali $i^{2,3}$,Elwalid F. Nasir ${ }^{2,3}$
}

\begin{abstract}
INTRODUCTION This study aimed to assess the association between toombak (smokeless tobacco) advertisement at point-of-sale (PoS) and its use among adolescents in Sudan.

METHODS A cross-sectional school-based and self-administered questionnaire study was conducted. Schools were randomly selected using a one-stage stratified sampling procedure, during 2013-2014, as part of a larger research project focusing on the use of toombak among secondary school students in Khartoum State, Sudan. The sample size was 1526 students. Data were collected on exposure to toombak advertisement, social acceptability, perceived accessibility to toombak, susceptibility, and toombak use.

RESULTS A total of $41.8 \%$ of the adolescents were exposed to an advertisement at PoS, while $12.5 \%$ perceived direct access to toombak, $5.3 \%$ reported that they were susceptible to use toombak, and $10.9 \%$ were ever toombak users. Exposure to the advertisement of toombak at PoS was found to be associated with the older age group $(44.3 \%)(\mathrm{p} \leq 0.05)$. Males were more than females $(45.2 \%$ vs $38.8 \%$; $\mathrm{p} \leq 0.05)$. Those exposed to toombak advertisements at PoS reported more social acceptability towards toombak ( $48.9 \%$ vs $37.6 \% ; \mathrm{p} \leq 0.001)$ and direct accessibility to toombak ( $68.8 \%$ vs $47.2 \% ; \mathrm{p} \leq 0.05)$. Ever toombak users reported higher exposure to advertisements than non-users ( $54.5 \%$ vs $40.3 \%$; $\leq \leq 0.001)$.

CONCLUSIONS Exposure to toombak advertisements at PoS was found to be high and associated with increased toombak use in Khartoum State, Sudan, in addition to increasing social acceptability to its use and perceived easy accessibility. The current law, which bans toombak advertisement and promotion at PoS, needs to be enforced.
\end{abstract}

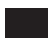

\section{AFFILIATION}

1 Oral and Maxillofacial Surgery Department, College of Dentistry, King Faisal University, Al-Ahsa, Saudi Arabia

2 Faculty of Dentistry, University of Science and Technology, Omdurman, Sudan

3 Department of Preventive Dentistry, College of Dentistry, King Faisal University, Al-Ahsa, Saudi Arabia
\end{abstract}

CORRESPONDENCE TO Hatim M. Almahdi. Oral and Maxillofacial Surgery Department, College of Dentistry, King Faisal University, PO Box 380, Al-Ahsa 31982, Saudi Arabia.

E-mail: hyagoob@kfu.edu.sa ORCID ID: https://orcid.org/00000001-8133-6216

\section{KEYWORDS}

toombak, snuff, smokeless tobacco, advertisement, point-of-sale

Received: 27 August 2019 Revised: 8 December 2019 Accepted: 23 December 2019

\section{INTRODUCTION}

Prevention of the initiation of tobacco use is a public health priority ${ }^{1}$. Tobacco use is a preventable cause of disease, disability, and death worldwide ${ }^{2}$. Tobacco use begins during adolescence, youth and young adulthood ${ }^{1}$. World Health Organization (WHO) defines 'Adolescents' as individuals aged 10-19 years and 'Youth' as aged 15-24 years. While 'Young' covers the age group 10-24 years ${ }^{3}$.

WHO Framework Convention on Tobacco
Control (FCTC) defined tobacco advertisement and promotion as 'any form of communication, recommendation or action with the aim, effect or likely effect of promoting a tobacco product or tobacco use either directly or indirectly'. Article 13 further requires that parties shall prohibit all tobacco advertisement and promotion ${ }^{4}$. Exposure to tobacco advertisement and promotion is linked to the initiation of use and increase in the prevalence among adolescents ${ }^{5}$. WHO estimates that one-third 
of adolescents' use of tobacco is a direct result of advertisement and promotion, and that a complete ban will decrease the tobacco epidemic ${ }^{5-7}$.

Tobacco control programs include the prohibition of all forms of advertisement and promotion, encompassing what appears on media, billboards, on packs and at point-of-sale (PoS); they are effective in reducing tobacco use as well as producing a concomitant decrease in tobacco-related health problems ${ }^{8}$.

PoS increasingly becomes an essential tool of the tobacco industry for promoting their products, due to the strict regulations on advertisement, which limit the promotional methods available to the tobacco industry ${ }^{9}$. Tobacco displays at PoS are present in most common marketing environments such as local stores, which are frequently visited by adolescents and which increase the possibility of encouraging initiation among them ${ }^{10,11}$.

Smokeless tobacco (SLT) products are mostly unmonitored, and there is a wide gap between them and smoked tobacco in terms of policy implementation, although evidence indicates that SLT use responds to control policies ${ }^{12,13}$. Moreover, SLT is promoted as being less harmful than smoking, despite its link to oral and other cancers and systemic diseases, with a reduced price and social acceptability. Therefore, there is an increase in SLT use, e.g. in the US by $62 \%^{14-16}$.

Sudan has a many forms of SLT known as toombak (snuff). The species Nicotiana rustica is used for the manufacture of toombak; a tobacco

Figure 1. Examples of advertisements at a point-of sale in Khartoum, Sudan

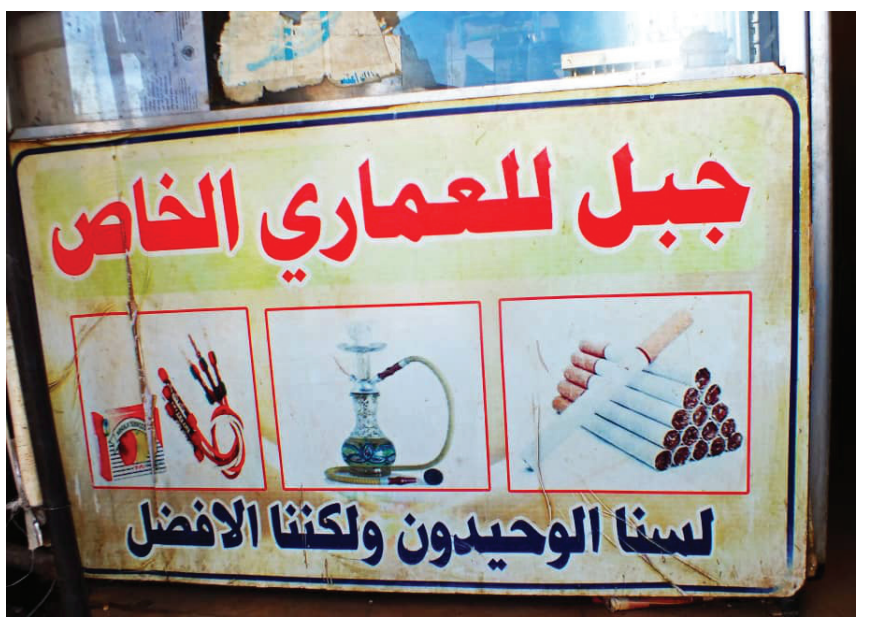

species with an unusually high content of nicotine and alkaloids, grown in the northwest of Sudan after the rainfall season. The plant is harvested after it turns to a yellow color and later stored for fermentation for weeks, it is then milled and stored for a year for ageing ${ }^{17}$. The product is mixed with natron (a mixture of natural forms of sodium carbonate, bicarbonate, chloride and sulfate minerals), to raise the $\mathrm{pH}$ for rapid absorption of the nicotine, and then water is added to the mixture, so that after about 2 hours, the mixture is ready for $\mathrm{use}^{18}$. Toombak is sold in small plastic bags each about $100 \mathrm{~g}$ and is used orally by insertion between lower gum and cheek or lip (dipping).

Toombak is considered as a risk factor for oral cancer because of the abnormally high concentration of tobacco specific nitrosamines, which are known to be carcinogenic, among other carcinogens produced during the fermentation, in addition to contamination and poor hygiene environment during processing ${ }^{17,19,20}$.

Among individuals aged 18 years, the average prevalence of toombak use was $38 \%$ among males and $10.9 \%$ among adolescents in Khartoum State ${ }^{21,22}$. Toombak can be purchased from many shops and the product is advertised extensively at PoS, where retailers tend to use attractive methods to draw buyers' interest without any age restrictions ${ }^{17,23}$. The trade names for toombak include El-Sanf (of high quality), Wad Amari (name of the person who has introduced it) and Sultan El-kaif (the power to improve one's state of mind) and other advertising to promote the strongest and powerful stimulant to

Figure 2. Examples of advertisements at a point-of sale in Khartoum, Sudan

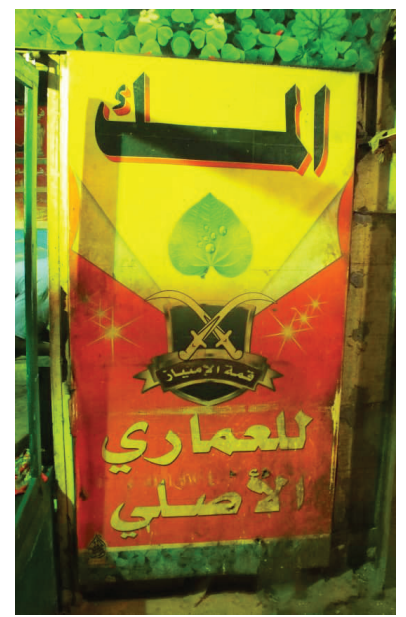


change the $\operatorname{mood}^{17}$ (Figures 1 and 2).

The prevention and control of SLT use is a complex health issue and has drawn inadequate attention from researchers and policymakers worldwide ${ }^{24}$. The present study measured the association between exposure to an advertisement at PoS and toombak use among adolescents (13-15 years) in Khartoum State, Sudan. In addition, the study aimed to assess the association of toombak use with demographic factors, social acceptability, intention to use, and perceived ease of access to toombak.

\section{METHODS}

This is a cross-sectional school-based study that was conducted in 2013-14, as part of a larger research project focusing on the use of toombak among secondary school students in Khartoum State, Sudan. Khartoum is the capital of Sudan and consists of three cities (Khartoum, Omdurman, and Khartoum North), including seven localities: Khartoum, Jabal Awaliya, Omdurman, Umbadda, Karary, Bahry, and Sharg Alnil. The educational system comprises private and public schools as well as separate schools for boys and girls.

\section{Sampling procedures}

The sampling procedure was part of a larger-scale study of secondary schools students' use of toombak ${ }^{21}$. A total of 28 schools were randomly selected, four from each locality (public/female, public/male, private/female, and private/male). All seven localities of the three cities were included in the sample. All students (census) aged 13-16 years who attended the 28 selected schools were eligible to participate in the study. Eligibility criteria required presence at the school at the time of the research and the provision by the student of informed consent. A total of 1670 students enlisted, representing an additional $9 \%$ to the calculated sample size, to account for incomplete questionnaires.

\section{Data collection}

The survey instrument was from the Global Youth Tobacco Survey (GYTS); a school-based survey designed to collect information from the students regarding exposure to the advertisement and toombak use. GYTS is an integral part of the Global Tobacco Surveillance System (GTSS), constituting questions about SLT, started by the WHO in $1999^{25}$.

A self-administered questionnaire was distributed in classroom settings in the absence of teachers but under the supervision of trained data collectors after standardized instructions about the purpose of the study. A written informed consent was obtained from participating students and their parents through the schools' administration.

Ethical clearance was obtained from the Ethical Committee of the Ministry of Health and Education, also from authorities in each locality and school. The questionnaire was translated from English to Arabic and subsequently back-translated into English by experts in both languages. A pilot study was conducted in two schools (male, female) including 60 students. It tested the accuracy of translation and understanding of the questions and was conducted before the administration of the survey in the selected schools. Based on the results of the pilot study, some minor adjustments were introduced to the survey instrument.

\section{Questions and variables}

Characteristics, including age group, parents' employment, and parents' education were measured. Also, exposure to toombak advertisement was measured by one question: 'during the past 30 days did you see any toombak promotion in the toombak shops?.

To assess social acceptability of toombak use (Cronbach's $a=0.54$ ), a sum variable was assessed by three questions: 'do you think toombak helps people feel more comfortable or less comfortable at celebrations, parties, or in other social gatherings?'; 'do you think those who are using toombak have more friends?'; and 'do you think those who are using toombak are more attractive?'.

Exposure to toombak advertisement at PoS was measured by one question: 'during the past 30 days did you see any toombak promotion in the toombak shops?'.

Two questions assessed the susceptibility of toombak use: 'if one of your best friends offered you toombak, would you use it?'; and 'at any time during the next 12 months do you think you will use toombak?'.

Perceived accessibility to toombak was measured 
by one question: 'how did you get toombak last time?'. Ever users were defined as having used toombak at least once or twice in their life $\mathrm{e}^{26}$.

\section{Statistical analyses}

Data were analyzed using the Statistical Package for the Social Sciences, version 20 (SPSS Inc. IL, U.S.A.). Descriptive analyses were performed using frequencies and percentages. Bivariate relationships between the dependent variable and each independent variable were assessed using cross-tabulation and chisquared test. Multivariable analysis was conducted using multiple logistic regression. Estimates were presented as odds ratios (ORs) and 95\% confidence intervals (CIs). Nagelkerkes $\mathrm{R}^{2}$ was calculated for the model.

\section{RESULTS}

A total of 1670 adolescents, aged $13-15$ years, participated in the study. More than half (53.4\%) were aged $<15$ years, and $53.6 \%$ were females (Table 1 ).

Less than half $(41.8 \%)$ of the adolescents were exposed to advertisement at PoS, and $12.5 \%$ perceived direct access to toombak, and 5.3\% reported that they were susceptible to use toombak, and $10.9 \%$ were ever toombak users (Table 2 ).

Exposure to the advertisement of toombak at PoS was found to be associated with older age with $44.3 \%$ aged $\geq 15$ years versus $38.9 \%$ aged $<15$ years reporting being exposed (pৎ0.05). Males were more exposed to advertisements than females ( $45.2 \%$ vs $38.8 \% ; \mathrm{p} \leq 0.05)$. Those who were exposed to toombak advertisements at PoS reported more social acceptability towards toombak use ( $48.9 \%$ vs $37.6 \%$; $\mathrm{p} \leq 0.001)$ and direct accessibility to toombak more than their counterparts ( $68.8 \%$ vs $47.2 \%$; $\mathrm{p} \leq 0.05$ ).

Those that perceived that they are susceptible to use toombak reported higher exposure to the advertisements than those who did not $(41.7 \%$ vs 47.6), but the difference was not statistically significant. Among the toombak users, exposure to the advertisements was higher than in those who were exposed among non-users $(54.5 \%$ vs $40.3 \%$; $\mathrm{p} \leq 0.001$ ) (Table 3 ).

The parameters associated with ever use of toombak were assessed through a regression analysis. Taking into account the respondents age, gender, social acceptability, perceived accessibility
Table 1. Frequencies and percentages of sociodemographic characteristics of the participants

$\begin{array}{lc}\text { Characteristics } & \\ \text { Age (years) } & 53.4(872) \\ <15 & 46.6(761) \\ \geq 15 & \\ \text { Gender } & 53.6(887) \\ \text { Female } & 46.4(768) \\ \text { Male } & \\ \text { Parent education } & 3.7(45) \\ \text { Not educated } & 96.3(1170) \\ \text { Educated } & \\ \text { Parent employment } & 4.3(70) \\ \text { Not employed } & 95.7(1544) \\ \text { Employed } & \end{array}$

Table 2. Frequencies and percentages of characteristics of the advertisement and promotion of toombak at point-of-sale

$\begin{array}{lc}\text { Characteristics } & \\ \text { Exposure to toombak advertisement } & 58.2(937) \\ \text { No } & 41.8(673) \\ \text { Yes } & \\ \text { Social acceptability of toombak user } & 62.5(1001) \\ \text { No } & 37.5(600) \\ \text { Yes } & \\ \text { Perceived accessibility to toombak } & 12.5(33) \\ \text { Direct } & 87.5(232) \\ \text { Indirect } & \\ \text { Susceptibility of toombak use } & 94.7(1532) \\ \text { No } & 5.3(86) \\ \text { Yes } & \\ \text { Ever toombak use } & 89.1(1465) \\ \text { Non-user } & 10.9(180) \\ \text { Ever user }\end{array}$

and exposure to the advertisement of toombak at PoS, the model explained $5.8 \%$ of the variance (Nagelkerke's $R^{2}=0.058$ ). Male and older aged respondents were more likely to be exposed to toombak advertisement at PoS (Table 4). Those perceived to have direct accessibility had a greater likelihood to be exposed to an advertisement than their counterparts ( $\mathrm{OR}=2.14$; 95\% CI: 0.94-4.88) (Table 4). 
Table 3. Percentages, frequencies and odds ratios with 95\% CI, of demographic characteristics, social acceptability, toombak accessibility, and susceptibility and use of toombak, by advertisement and promotion

\begin{tabular}{|c|c|c|c|}
\hline \multirow[t]{2}{*}{ Characteristics } & \multicolumn{2}{|c|}{ Advertisement for toombak } & \multirow[t]{2}{*}{ OR $\left(95^{\circ} \% \mathrm{CI}\right)$} \\
\hline & Yes & No & \\
\hline \multicolumn{4}{|l|}{ Age (years) } \\
\hline$<15$ & $38.9(332)$ & $61.1(522)$ & $1.24(1.02-1.52)$ \\
\hline$\geq 15$ & $44.3(325)^{*}$ & $55.7(409)$ & \\
\hline \multicolumn{4}{|l|}{ Gender } \\
\hline Female & $38.8(336)$ & $61.2(529)$ & $1.30(1.06-1.58)$ \\
\hline Male & $45.2(336)^{*}$ & $54.8(407)$ & \\
\hline \multicolumn{4}{|c|}{ Social acceptability of toombak user } \\
\hline No & $37.6(366)$ & $62.4(608)$ & $1.58(1.29-1.95)$ \\
\hline Yes & $48.9(287)^{* *}$ & $51.1(300)$ & \\
\hline \multicolumn{4}{|c|}{ Perceived accessibility to toombak } \\
\hline Direct & $68.7(22)^{*}$ & $31.3(10)$ & $0.40(0.18-0.89)$ \\
\hline Indirect & $47.2(109)$ & $52.8(122)$ & \\
\hline \multicolumn{4}{|c|}{ Susceptibility to use toombak } \\
\hline No & $41.7(622)$ & $58.3(871)$ & $1.27(0.82-1.97)$ \\
\hline Yes & $47.6(40)$ & $52.4(44)$ & \\
\hline \multicolumn{4}{|l|}{ Ever toombak use } \\
\hline Non-user & $40.3(574)$ & $59.7(850)$ & $0.56(0.41-0.77)$ \\
\hline Ever user & $54.5(96)^{* *}$ & $45.5(80)$ & \\
\hline
\end{tabular}

${ }^{*} \mathrm{p} \leq 0.5 .{ }^{* *} \mathrm{p} \leq 0.001$

Table 4. Ever toombak use regressed upon age group, gender, social acceptability, perceived accessibility and susceptibility of toombak use, and exposure to advertisement of toombak at point-of-sale

$\begin{array}{ll}\begin{array}{l}\text { Characteristics } \\ \text { Age (years) }\end{array} & \begin{array}{l}\text { Arer toombalk use } \\ \text { OR }\left(95^{\circ} \mathrm{CI}\right)\end{array} \\ <15 & 1.70(0.96-3.02) \\ \geq 15 & 1 \\ \text { Gender } & 4.86(2.65-8.93)^{*} \\ \text { Female } & \\ \text { Male } & \\ \text { Social acceptability of } & 1 \\ \text { toombak user } & 1.53(0.86-2.73) \\ \text { No } & \\ \text { Yes } & \\ \text { Perceived accessibility to } & 1 \\ \text { toombak } & 0.59(0.25-1.35) \\ \text { Direct } & \\ \text { Indirect } & 1 \\ \text { Exposure to advertisement } & 1.40(0.79-2.48) \\ \text { No } & \\ \text { Yes } & \end{array}$

\section{DISCUSSION}

This study examined the possible association between exposure to toombak advertisement at PoS and its use and other related variables among adolescents in Khartoum State, Sudan. The PoS environment regarding promotion and advertisement restrictions is often overlooked in tobacco control programs, especially in Sudan. Besides, no previous study has focused on the effect of advertisement at PoS on toombak use.

In this study, less than half of the adolescents reported exposure to advertisements of toombak at PoS. This is similar to a study from Indonesia, where less than half of the participants reported exposure to SLT at $\mathrm{PoS}^{27}$. However, in India, $59 \%$ of the participants reported exposure to PoS advertisement while more than two-thirds of adolescents in New Zealand noticed displays and advertisements of tobacco products ${ }^{6,28}$.

The advertisement at PoS aims to increase product exposure, visibility and normalization of the tobacco product, and this occurs through the principles of inform, promote, create interest and 
curiosity, encourage trial and experimentation, and thus in an underestimate of its health hazards ${ }^{9,29}$. It seems that the exposure of male adolescents to the advertisement at PoS is higher than for females, and this is reflected in this study, where cultural and social reasons may explain this, as male adolescents are more likely to spend time outdoors than females ${ }^{30,31}$.

In Sudan, there are real challenges for enforcing prohibitions on advertising at PoS, as the law bans advertising at PoS for smoked tobacco but not toombak; also, there are no exact data on compliance to this $\mathrm{law}^{8,20}$. A report reveals that only $9 \%$ of the countries have high compliance related to the ban on advertisement, promotion and sponsorship of SLT, even though $30 \%$ have implemented a comprehensive ban at $\mathrm{PoS}^{13}$.

Evidence provided in the literature confirms that adolescents who are exposed to tobacco advertising, or are receptive to it, are more likely to have tried tobacco or have become users ${ }^{32-34}$. The current study showed a significant association between toombak users and the exposure to the advertisement of toombak at PoS. Moreover, this study reported that noticing PoS displays more frequently is associated with an increased likelihood of reporting direct access to toombak, which in turn leads to an increase in the susceptibility of Sudanese adolescents to toombak and eventually to becoming users ${ }^{21}$.

Nevertheless, in the logistic regression model, the exposure to the advertisement of toombak at PoS was not a strong predictor of becoming a future user, but the likelihood was increased 1.5 times $^{21}$. This agrees with other studies where SLT susceptibility and use were associated with increased exposure to PoS display ${ }^{35,36}$, but in contrast to a study from India where a ban was associated with reduced SLT use but not with susceptibility and perceived easy $\operatorname{access}^{37}$.

This study showed higher social acceptability among adolescents who reported exposure to the advertisement, and that is supported by the change in the marketing industry's desire for promoting SLT as a more socially acceptable product that can be used indoors ${ }^{38}$. Also, tobacco users who sometimes use other products individually or within their peer network, are associated with more favourable perceptions of $\mathrm{SLT}^{39}$.

\section{Strengths and limitations}

There are distinct strengths and limitations to this study. The study is a cross-sectional school-based sample in Khartoum State, therefore limiting the generalizability and precluding causal inferences to other parts of the country. Nevertheless, Khartoum State is highly populated and represents the ethnic and cultural diversity of the country; it provides valuable information about toombak use and advertisement at PoS and adolescents' toombak use. The large sample size, randomization of the participants, and the reliability and validity of the questions used, are strengths of the study.

\section{CONCLUSIONS}

The exposure to the advertisement of toombak at PoS among male and older adolescents was found to be high and associated with increased toombak use in Khartoum State, Sudan. This was in addition to increasing the social acceptability of its use and perceived easy accessibility. The advertisement and promotion at PoS of toombak need attention to enforce the law, which bans it.

\section{REFERENCES}

1. National Center for Chronic Disease Prevention and Health Promotion (US) Office on Smoking and Health. Preventing Tobacco Use Among Youth and Young Adults: A Report of the Surgeon General. Atlanta (GA): Centers for Disease Control and Prevention (US); 2012. PMID:22876391.

2. National Center for Chronic Disease Prevention and Health Promotion. Preventing Initiation of Tobacco Use: Outcome Indicators for Comprehensive Tobacco Control Programs-2014. Atlanta, GA: Centers for Disease Control and Prevention, National Center for Chronic Disease Prevention and Health Promotion, Office on Smoking and Health; 2014. https://www.cdc.gov/tobacco/ tobacco_control_programs/surveillance_evaluation/ preventing_initiation/pdfs/preventing_initiation.pdf. Accessed December 3, 2019.

3. Word Health Organization. Adolescent health in the South-East Asia Region. http://www.searo.who.int/ entity/child_adolescent/topics/adolescent_health/en/. Accessed December 3, 2019.

4. World Health Organization. WHO Framework Convention on Tobacco Control. Geneva, Switzerland: World Health Organization; 2003. http://apps.who.int/iris/bitstream/ handle/10665/42811/9241591013.pdf? sequence $=1$. Accessed December 3, 2019.

5. World Health Organiztion. WHO Report on the 
global tobacco epidemic, 2013: enforcing bans on tobacco advertising, promotion and sponsorship. Geneva, Switzerland: World Health Organization; 2013. http://apps.who.int/iris/bitstream/ handle/10665/85380/9789241505871_eng. pdf; j ses sionid=CCEEE 93 C 0956418 A 79795 77509D8D5C9? sequence=1. Accessed December 3, 2019.

6. Paynter J, Edwards R. The impact of tobacco promotion at the point-of-sale: a systematic review. Nicotine Tob Res. 2009;11(1):25-35. doi:10.1093/ntr/ntn002

7. Levy T, Mays D, Boyle RG, Tam J, Chaloupka FJ. The effect of tobacco control policies on US smokeless tobacco use: a structured review. Nicotine Tob Res. 2016;20(1):311. doi:10.1093/ntr/ntw291

8. World Health Organization. Evidence brief Tobacco pointof-sale display bans. Geneva, Switzerland; 2017. http:// www.euro.who.int/_data/assets/pdf_file/0005/339233/ who-evidence-brief-pos-ban-eng.pdf. Accessed December 3, 2019.

9. Lavack AM, Toth G. Tobacco point-of-purchase promotion: examining tobacco industry documents. Tob Control. 2006;15(5):377-384. doi:10.1136/tc.2005.014639

10. Henriksen L, Feighery EC, Schleicher NC, Haladjian $\mathrm{HH}$, Fortmann SP. Reaching youth at the point-ofsale: cigarette marketing is more prevalent in stores where adolescents shop frequently. Tob Control. 2004;13(3):315-318. doi:10.1136/tc.2003.006577

11. Slater SJ, Chaloupka FJ, Wakefield M, Johnston LD, O'Malley PM. The impact of retail cigarette marketing practices on youth smoking uptake. Arch Pediatr Adolesc Med. 2007;161(5):440-445. doi:10.1001/archpedi.161.5.440

12. World Health Organization, National Institute of Cancer Prevention and Research. Global smokeless tobacco control policies and their implementation. Noida, India: National Institute of Cancer Prevention and Research, 2017. https://untobaccocontrol.org/kh/smokelesstobacco/wp-content/uploads/sites/6/2018/04/Globalsmokeless-NICPR-19418-1.pdf. Accessed December 3, 2019.

13. Mehrotra R, Yadav A, Sinha DN, et al. Smokeless tobacco control in 180 countries across the globe: call to action for full implementation of WHO FCTC measures. Lancet Oncol. 2019;20(4):e208-e217. doi:10.1016/S1470-2045(19)30084-1

14. Hawkins SS, Bach N, Baum CF. Impact of tobacco control policies on adolescent smokeless tobacco and cigar use: a difference-in-differences approach. BMC Public Health. 2018;18(1):154. doi:10.1186/s12889-018-5063-z

15. Mejia AB, Ling PM, Glantz SA. Quantifying the effects of promoting smokeless tobacco as a harm reduction strategy in the USA. Tob Control. 2010;19(4):297-305. doi:10.1136/tc.2009.031427

16. Peeters S, Gilmore AB. Understanding the emergence of the tobacco industry's use of the term tobacco harm reduction in order to inform public health policy. Tob Control. 2015;24(2):182-189. doi:10.1136/tobaccocontrol-2013-051502
17. Idris AM, Ibrahim YE, Warnakulasuriya KA, Cooper DJ, Johnson NW, Nilsen R. toombak use and cigarette smoking in the Sudan: estimates of prevalence in the Nile state. Prev Med. 1998;27(4):597-603. doi:10.1006/pmed.1998.0331

18. Ahmed MKJM. Analytic Study of the Role of Namal in toombak. Khartoum, Sudan: Sudan University of Science and Technology; 2016. http://repository.sustech.edu/ handle/123456789/14347. Accessed August 27, 2019.

19. Hassanin A, Idris A. Attribution of oral cancer in the Sudan to toombak dipping. Translational Research in Oral Oncology. 2017;2:2057178X1668572. doi:10.1177/2057178X16685729

20. Idris AM, Ibrahim SO, Vasstrand EN, et al. The Swedish snus and the Sudanese toombak: are they different? Oral Oncol. 1998;34(6):558-566. doi:10.1016/s1368-8375(98)00047-5

21. Almahdi HM, Ali RW, Nasir EF, Åstrøm AN. Sociocognitive correlates of intention to use toombak: a cross-sectional study among students (13-16 years) in Khartoum state, Sudan. BMC Public Health. 2017;18(1):88. doi:10.1186/s12889-017-4606-z

22. Ahmed HG. Survey on knowledge and attitudes related to the relation between tobacco, alcohol abuse and cancer in the northern state of Sudan. Asian Pac J Cancer Prev. 2013;14(4):2483-2486. doi:10.7314/apjcp.2013.14.4.2483

23. World Health Organization. WHO report on the global tobacco epidemic, 2017: monitoring tobacco use and prevention policies. Geneva, Switzerland: World Health Organization; 2017. https://apps.who.int/iris/bitstream/ handle/10665/255874/9789241512824-eng.pdf. Accessed December 3, 2019.

24. Mehrotra R, Sinha DN. Global challenges in smokeless tobacco control. Indian J Med Research. 2018;148(1):1-3. doi:10.4103/ijmr.ijmr_32_18

25. Centers for Disease Control and Prevention. Global Global Youth Tobacco Survey (GYTS) - Overview. https:// nccd.cdc.gov/GTSSDataSurveyResources/Ancillary/ Documentation.aspx?SUID $=1 \& D O C T=1$. Accessed December 3, 2019.

26. World Health Organization. Methods for Evaluating Tobacco Control Policies. In: IARC Handbooks of Cancer Prevention. Geneva, Switzerland: World Health Organization; 2008. https://publications.iarc.fr/ Book-And-Report-Series/Iarc-Handbooks-Of-CancerPrevention/Methods-For-Evaluating-Tobacco-ControlPolicies-2008. Accessed December 3, 2019.

27. Prabandari YS, Dewi A. How do Indonesian youth perceive cigarette advertising? A cross-sectional study among Indonesian high school students. Glob Health Action. 2016;9:30914. doi: 10.3402/gha.v9.30914

28. Khariwala SS, Garg A, Stepanov I, Gupta PC, Ahluwalia JS, Gota V, Chaturvedi P. Point-of-Sale Tobacco Advertising Remains Prominent in Mumbai, India. Tob Regul Sci. 2016;2(3):230-238. doi:10.18001/TRS.2.3.3 
29. Pollay RW. More than meets the eye: on the importance of retail cigarette merchandising. Tob Control. 2007;16(4):270-274. doi:10.1136/tc.2006.018978

30. Huong LTT, Long TK, Van Anh TT, et al. Exposure to Tobacco Advertising, Promotion Among the Adult Population in Vietnam and Its Implications for Public Health. Asia Pac J Public Health. 2017;29(7):569-579. doi:10.1177/1010539517735630

31. Lienemann BA, Rose SW, Unger JB, et al. Tobacco Advertisement Liking, Vulnerability Factors, and Tobacco Use among Young Adults. Nicotine Tob Res. 2018;21(3):300-308. doi:10.1093/ntr/nty220

32. Pierce JP, Sargent JD, Portnoy DB, et al. Association Between Receptivity to Tobacco Advertising and Progression to Tobacco Use in Youth and Young Adults in the PATH Study. JAMA Pediatr. 2018;172(5):444-451. doi:10.1001/jamapediatrics.2017.5756

33. Lovato C, Watts A, Stead LF. Impact of tobacco advertising and promotion on increasing adolescent smoking behaviours. Cochrane Database Syst Rev. 2011;(10):CD003439. doi:10.1002/14651858.cd003439.pub2

34. Beleva Y, Pike J, Miller S, Xie B, Ames S, Stacy A. Share of Advertising Voice at the Point-of-Sale and Its Influence on At-Risk Students' Use of Alternative Tobacco Products. Nicotine Tob Res. 2018;21(7):903-910. doi:10.1093/ntr/nty152 2018

35. Bogdanovica I, Szatkowski L, McNeill A, Spanopoulos D, Britton J. Exposure to point-of-sale displays and changes in susceptibility to smoking: findings from a cohort study of school students. Addiction. 2015;110(4):693-702. doi:10.1111/add.12826

36. Patel D, Kassim S, Croucher R. Tobacco promotion and availability in school neighborhoods in India: a crosssectional study of their impact on adolescent tobacco use. Asian Pac J Cancer Prev. 2012;13(8):4173-4176. doi:10.7314/apjcp.2012.13.8.4173

37. Mistry R, Pednekar MS, McCarthy WJ. Compliance with point-of-sale tobacco control policies and student tobacco use in Mumbai, India. Tob Control. 2018;28(2):220-226. doi:10.1136/tobaccocontrol-2018-054290

38. Timberlake DS. Advertising receptivity and youth initiation of smokeless tobacco. Subst Use Misuse. 2016;51(9):10771082. doi:10.3109/10826084.2016.1160115

39. Berg CJ, Stratton E, Schauer GL, Lewis M, Wang Y, Windle M, Kegler M. Perceived harm, addictiveness, and social acceptability of tobacco products and marijuana among young adults: marijuana, hookah, and electronic cigarettes win. Subst Use Misuse. 2015;50(1):79-89. doi:10.3109/10826084.2014.958857
CONFLICTS OF INTEREST

The authors have completed and submitted the ICMJE Form for Disclosure of Potential Conflicts of Interest and none was reported.

FUNDING

There was no source of funding for this research.

PROVENANCE AND PEER REVIEW

Not commissioned; externally peer reviewed. 